\title{
REFLEXÕES SOBRE A GESTÃO DE RECURSOS HÍDRICOS NO ESTADO DA BAHIA
}

\section{ALICE GONZALEZ BORGES*}

1. A estruturação do sistema nacional de gerenciamento dos recursos hídricos é, verdadeiramente, uma das necessidades que se configuram mais prioritárias e urgentes para a coletividade brasileira, na era atual. Trata-se de assegurar aos cidadãos, mediante um conjunto eficiente de instrumentos legislativos e de ações gerenciadoras e fiscalizadoras sintonizadas, a garantia de que a água, recurso natural essencial à vida, ao desenvolvimento econômico e ao progresso social, se torne acessível a todos, em níveis satisfatórios de quantidade e de qualidade.

Mais ainda, a Constituição impõe, a todos os brasileiros, não só governantes como cidadãos, dentro do que estatui o seu art. 225, a inarredável responsabilidade de também assegurar pela utilização nacional e adequada preservação de tais bens essenciais da natureza, a própria qualidade de vida das gerações futuras.

$O$ tratamento da matéria, em sede normativa constitucional e legal, se apresenta particularmente desafiante, tendo em vista as peculiaridades de nosso ordenamento jurídico-constitucional, estruturado em bases federativas, dotado de uma tríplice esfera de competências normativas e organizacionais autônomas, tal como assegurado pelo art. 18 da Carta Magna, que se interpenetram, se relacionam, e às vezes até colidem entre si.

Demais disso, a extrema diversidade climática e geográfica de nosso país continente, suas enormes dimensões e distâncias, bem como a má distribuição, se podemos dizer assim, das riquezas hídricas de suas numerosas bacias, - umas cortadas por grandes e numerosos rios perenes, outras constantemente assoladas pelas secas - configuram uma problemática de solução bastante difícil e intrincada.

Talvez seja este aspecto - o da adequada a harmônica gestão dos recursos hídricos em nosso país - um dos que mais sinalizam para as necessidades da efetiva implantação e desenvolvimento, entre nós, do federalismo regional, ou cooperativo, tão sonhado e defendido por juristas do porte de PAULO BONAVIDES, JOSÉ

* Professora Titular das Faculdades de Direito da Universidade Católica de Salvador e da Universidade UNIFACS de Salvador.

R. Dir. Adm.,

Rio de Janeiro, 213: 89-101,

jul./set. 1998 
ALFREDO BARACHO e RAUL MACHADO HORTA. Pois nada mais une tanto os interesses comuns de municípios e estados. do que o acesso - ou falta dele a esses bens essenciais da natureza. bem como a forma de sua exploração racional. demandando a busca de soluções também comuns.

2. A Constituição Federal dispõe a respeito do domínio das águas, em dois planos distintos: federal $\mathrm{c}$ estadual.

São bens da União. segundo o art. 20, inciso III. os lagos, rios e quaisquer correntes de água:

a) situados em terrenos de seu domínio;

b) os que banham mais de um Estado;

c) os que servem de limites com outros países, ou se estendam a território estrangeiro, ou que dele provenham.

Incluem-se, ainda, entre os bens da União, os potenciais de energia hidráulica (art. 20, inciso VIII) e os recursos minerais, inclusive do sub-solo (art. 20, inciso IX).

Já quando aos Estados federados, a Constituição inclui, como bens do seu domínio, as águas superficiais ou subterrâneas, fluentes, emergentes e em depósito, ressalvadas, neste último caso, as decorrentes de obras da União (art. 26, inc. I), tais como açudes e barragens.

3. Legislar sobre águas, em geral, é da competência privativa da União, nos precisos termos do art. 22, inciso IV, da Constituição. Consequientemente, é à união que compete, conforme dispõe o art. 21, inciso XIX. instituir o SISTEMA NACIONAL DE GERENCIAMENTO DE RECURSOS HÍDRICOS, bem como definir critérios para a outorga de direitos de seu uso.

Entretanto, poderá lei complementar autorizar os Estados-Membros a legislar sobre questões específicas pertinentes à disciplina dos recursos hídricos art. 22, parágrafo único. Independentemente de tal autorização, os Estados podem dispor sobre o aproveitamento dos seus bens e a utilização dos recursos hídricos sob o seu domínio, nos termos da competência que lhe conferem os arts. $25, \S 1^{\varrho}$ (competência remanescente), e 26, incisos I e II da Constituição Federal. em assim, dispõe os Estados-Membros de competência concorrente para dispor sobre recursos naturais (art. 24, inc. VI).

Assim, se não podem os Estados-Membros legislar sobre águas, com possíveis repercussões estratégicas ou geopolíticas, em detrimento do equilíbrio federativo da República, nada impede que instituam por lei sua política hídrica de natureza ambiental, para planejar o abastecimento e o saneamento e disciplinar a política administrativa das suas reservas hídricas, constitucionalmente reconhecidas como integrantes do seu patrimônio, quais sejam as explicitadas no art. 26. inc. I.

4. Mesmo porque é bem de ver que, sobre a matéria de saneamento básico, que abarca também o abastecimento de água, e se acha. portanto, estritamente relacionada com a gestão de recursos hídricos, à União somente compete, nos termos do art. 21, inc. XX-CF, instituir diretrizes básicas, a serem complementadas pela legislação dos Estados.

Quanto aos Municípios, sua competência legiferente, no particular, é inafastável, pela própria dicção do Texto Maior, no que diga respeito à integração de seu poder 
de suplementar a legislação federal e a estadual, no que couber (art. 30 , inc. II), e do de dispor sobre assuntos de interesse local (art. 30, inc. I), ainda quando pertinentes aos recursos hídricos.

Por outro lado, na medida em que é da inafastável competência do Município, segundo o art. 30, inc. V, organizar e prestar os serviços públicos de interesse local, é também de sua induvidosa competência dispor sobre a gestão dos serviços de abastecimento de água, no âmbito de sua base territorial, porque, no caso, o assunto diz respeito a um interesse local evidentemente predominante sobre qualquer outro, estadual ou federal.

5. Quanto aos serviços e instalações de energia elétrica e ao aproveitamento energético dos cursos d'água, firma a Constituição, no art. 21, inciso XII, alínea b, a competência da União para explorá-los, diretamente ou mediante concessão ou permissão, porém em articulação com os Estados onde se situam os potenciais hidroenergéticos.

Por outro lado, é assegurada, conforme dispuser a lei, a participação dos Estados, do Distrito Federal e dos Municípios, bem como de órgãos da administração direta da União, no resultado da exploração de recursos hídricos, para fins de geração de energia elétrica e de outros recursos minerais no respectivo território (art. 20, $\S 1^{\mathbf{Q}}$ ), bem como a compensação financeira por essa exploração.

6. No que diz respeito, propriamente, aos recursos hídricos em geral, a Constituição estabeleceu, no art. 23, inciso XI, a competência comum da União, Estados, Distrito Federal e dos Municípios, para registrar, acompanhar e fiscalizar as concessões de direitos de pesquisa e exploração de recursos hídricos e minerais em seus territórios.

A Emenda Constitucional no 19, de 4 de junho de 1998, deu uma nova redação ao art. 241 do Texto Maior, passando a dispor que:

“Art. 241. A União, os Estados, o Distrito e os Municipios disciplinarão, por meio de lei, os consórcios públicos e os convênios de cooperação entre os entes federados, autorizando a gestão associada de serviços públicos, bem como a transferência total ou parcial de encargos, serviços, pessoal e bens essenciais à continuidade dos serviços transferidos".

Desta sorte, novas e amplas perspectivas se abrem, com essa Emenda, para que seja efetivamente viabilizado o exercício da competência comum das ordens federadas para a gestão associada da exploração dos recursos hídricos existentes em bacias hidrográficas comuns a seus respectivos territórios, através da disciplina estabelecida em consórcio públicos, interestaduais ou intermunicipais, conforme o caso.

Completando-se o esboço do quadro do tratamento constitucional da matéria pertinente aos recursos hídricos, nem há de esquecer-se que, ao dispor sobre as regiōes metropolitanas e microrregiões, no seu artigo $25, \S 3^{\circ}$, a Constituição Federal estatui sobre a integração da organização, planejamento e a execução de funções públicas de interesse comum de município limítrofes delas participantes, o que também pode aplicar-se ao conjunto de municípios, integrantes de uma mesma região metropolitana, ou microrregião, que possuam uma bacia hidrográfica comum. 
Todos esses aspectos especiais apontam, na Constituição de 1988, como já observamos, para uma expressiva tendência no sentido da efetiva estruturação do tão desejável federalismo regional ou de cooperação, que tornaria mais viável o governo de um país de tão grandes dimensões geográficas e de tantas peculiaridades regionais e locais, pela efetiva realização do objetivo republicano insculpido no art. $3^{\circ}$, inciso III, da Constituição.

7. Dentro desse quadro geral traçado pela Constituição, é que veio a situar-se a legislação federal regedora da matéria pertinente aos recursos hídricos.

Embora datado de 1934, o Código de Águas (Decreto Federal $n^{2} 24.643 / 34$ ) se encontra ainda vigente em algumas de suas disposições, que resistiram à sucessão de várias Constituições supervenientes desde então, estando recepcionandas pelo ordenamento jurídico-constitucional vigente. É o caso, por exemplo, dos seus artigos 45 a 52, respeitantes à disciplina da derivação das águas.

Foi, porém, a Lei $\mathrm{n}^{0}$ 9.433, de 8 de janeiro de 1997 , que veio a regular o inciso XIX do art. 21 da Constituição Federal, instituindo a POLÍTICA NACIONAL DE RECURSOS HÍDRICOS. Ao fazê-lo, definiu os seus fundamentos (art. $1^{\circ}$, incisos I a VI), os seus objetivos (art. $2^{-}$, incisos I a III), e suas diretrizes gerais de ação (art. $3^{\circ}$, incisos I a VI), bem como seus principais instrumentos, quais sejam:

a) os Planos de Recursos Hídricos, planos diretores de longo prazo, que orientam a implementação da Política Nacional de Recursos Hídricos, bem como o gerenciamento de tais recursos;

b) o enquadramento dos corpos de água em classes, segundo os seus usos preponderantes;

c) a forma de outorga dos direitos de uso de recursos hídricos;

d) a cobrança pelo uso dos recursos hídricos;

e) o sistema de informações sobre recursos hídricos.

$\mathrm{Na}$ implementação da Política Nacional de Recursos hídricos, deverá ser descentralizada a gestão dos referidos recursos, com vistas a contar com a participação do Poder Público, dos usuários e das comunidades.

Nesse sentido, visa-se à articulação do planejamento de recursos hídricos com os dos setores usuários e com os planejamentos em níveis regional, estadual e nacional, devendo a União atuar em conjunto com os Estados, com vistas ao gerenciamento dos recursos hídricos de interesse comum, podendo, inclusive, delegar-lhes a competência para a outorga do direito de uso de recursos hídricos do domínio da União (art. 14, § $1^{9}$ ).

Convém ressaltar que, na definição da Política Nacional de Recursos Hídricos, referida Lei prevê, também, a integração das políticas locais de saneamento básico, de uso, ocupação e conservação do solo e de preservação ambiental, a cargo dos Poderes Executivos do Distrito Federal e dos Municípios, com as políticas federal e estadual de recursos hídricos.

Tal previsão legal é extremamente oportuna, uma vez que a interação das atividades em tais áreas afins poderá contribuir para obviar as dificuldades legais e institucionais decorrentes da possibilidade, sempre presente, da ocorrência de superposições e conflitos de competência, previsíveis e até naturais, na sistemática de um 
País de organização federativa, mas que podem vir a prejudicar, afinal, a otimização do planejamento de recursos hídricos.

8. A Lei 9.433 cria, mais, o SISTEMA NACIONAL DE GERENCIAMENTO DE RECURSOS HÍDRICOS (art. 32), como o objetivo de implementar a política nacional de recursos hídricos e coordenar a gestão das águas, arbitrando administrativamente os conflitos relacionados com os recursos hídricos.

O Sistema Nacional de Gerenciamento dos Recursos Hídricos é integrado pelos seguintes órgãos:

I) o Conselho Nacional de Recursos Hídricos, órgão colegiado composto de representantes dos Ministérios e Secretarias da Presidência da República com atuação no gerenciamento ou no uso dos recursos hídricos, e dos representantes dos Conselhos Estaduais de Recursos Hídricos, dos usuários e das organizações civis ligada à área;

II) os Conselhos de Recursos Hídricos dos Estados e do Distrito Federal;

III) os Comitês de Bacia Hidrográfica;

IV) os órgãos dos poderes públicos federais, estaduais e municipais, cujas competências se relacionem com a gestão de recursos hídricos;

V) as Agências de Águas.

Os Comitês de Bacia Hidrográfica deverão integrar e harmonizar a ação da União, bem como dos Estados e Municípios, cujos territórios se situem na área de atuação de bacias, sub-bacias hidrográficas ou grupos de bacias ou sub-bacias contíguas, bem como dos usuários das águas respectivas, e das entidades civis de recursos hídricos, com comprovada atuação na bacia.

São seus órgãos executivos as Agências de Águas, cujas amplas competências e requisitos de criação se acham definidos nos arts. 43 e 44 da Lei supra citada.

Ainda a propósito da legislação federal pertinente aos recursos hídricos, cumpre lembrar que a matéria é intimamente relacionada com a de outras leis especiais disciplinadoras de assuntos conexos, tais como a de Proteção ao Meio Ambiente (Lei 9.638/81, recentemente alterada pela de $\mathrm{n}^{0}$ 9.605/98); aquela, prevista no Código de Mineração, com a redação dada pela Lei 9.314/96, em seu art. 10, incs. IV e V, sobre águas minerais em fase de lavra e jazidas subterrâneas; a da nova lei $\mathbf{n}^{2}$ 9.427, de 26 de dezembro de 1996, sobre energia elétrica; a da legislação especial sobre combate às secas.

Tem-se, pois, uma intrincada e desafiante rede de legislações especiais federais interrelacionadas, que, de uma forma ou de outra, incidem sobre a matéria respeitante à gestão de recursos hídricos e interferem e repercutem no seu disciplinamento.

9. A Constituição Estadual da Bahia, de 1989, dispôs largamente, no capítulo $\mathrm{V}$ do Título VI, intitulado DA POLÍTICA HÍDRICA E MINERAL. (arts. 198 a 204).

Embora seja cronologicamente bem anterior à Lei 9.433./97, harmoniza-se com os seus princípios e fundamentos essenciais, já mencionados.

Assim é que o constituinte estadual prevê, no seu art. 173, o desenvolvimento de uma ação harmônica que associe a conservação da natureza com a defesa do solo, do clima, da vegetação e dos recursos hídricos. Dispõe, ainda, no art. 198, sobre os fundamentos da política hídrica e mineral, que há de ser descentralizada, participa- 
tiva e integrada, em relação aos demais recursos naturais (inc. 1), propiciando-se o uso múltiplo das águas, com prioridade para o abastecimento das populações (inc. $\mathrm{V}$ ), e instituindo-se mecanismos de concessão, permissão e autorização para uso da água sob jurisdição estadual, pelo órgão público competente (inc. VI).

Determina, no art. 199, a instituição do Plano Estadual de Recursos Hídricos, mediante a congregação de organismos estaduais e municipais para a gestão destes recursos, em uma ação integrada que congregue:

a) a utilização racional das águas superficiais e subterrâneas;

b) o aproveitamento múltiplo dos recursos hídricos;

c) a proteção das águas contra ações que possam comprometer o seu uso, atual ou futuro:

d) a defesa contra a seca, enchentes, poluição e outros eventos críticos correlatos;

e) o rigoroso controle dos impactos ambientais negativos resultantes de aproveitamento dos recursos hídricos, obrigando as empresas, quando pelos mesmo responsáveis, à recomposição do meio ambiente, na área de abrangência de sua respectiva bacia hidrográfica (art. 202 e parágrafo único).

Prevê, mais, a possibilidade de cobrança pela utilização dos recursos hídricos, segundo as características e o porte da utilização, as peculiaridades de cada bacia hidrográfica e as condições econômicas dos usuários (art. 200, I, II e III).

Prioriza a realização de programas de irrigação e de eletrificação rural, em áreas próximas de rios perenes, barragens, lagos e manaciais (art. 203); assegura o emprego de recursos financeiros decorrentes da exploração de potenciais de energia hidráulica, petróleo, gás e outros recursos minerais, de forma a garantir a adequada gestão dos recursos hídricos (art. 204); bem assim, a compensação financeira dos Municípios que sofram impactos decorrentes dessas atividades (art. 204, parágrafo único).

10. Foi à luz de tais salutares princípios que a lei estadual baiana de $n^{\circ} 6.855$, de 12 de maio de 1995, veio a dispor sobre a política, o gerenciamento e o plano estadual de recursos hídricos, estabelecendo:

a) princípios básicos (art. $2^{\underline{o}}$, I a IV);

b) diretrizes da Política Estadual de Recursos Hídricos (art. 3o, I a VII), nas quais se harmonizam o equilíbrio do desenvolvimento regional (inc. I), e a maximização dos benefícios econômicos e sociais resultantes do aproveitamento múltiplo ou integrado dos recursos hídricos;

c) a proteção das bacias hidrográficas e das águas subterrâneas contra ações que possam comprometer seu uso atual e o futuro, tais como a poluição, exploração excessiva ou não controlada, eventos hidrológicos críticos, secas, inundações ou erosão.

A Política Estadual de Recursos Hídricos tem por órgão gestor a Superintendência de Recursos Hídricos, autarquia vinculada à Secretaria Estadual de Saneamento e Recursos Hídricos. São seus principais instrumentos o Plano Estadual de Recursos Hidricos, cujas metas são definidas no art. 10 (incisos I a XI), a outorga do direito de uso dos recursos hídricos (arts. 12 e 13), e a cobrança pelo direito de uso das águas (arts. 12 e 13).

Em princípio, a lei estadual baiana antecipou-se, em certos aspectos, à legislação federal superveniente, e com ela se harmoniza, num fenômeno que ocorre freqüentemente com as legislações estaduais. 
Há uma ligeira discrepância da lei estadual baiana, entretanto, com a legislação federal que the sobreveio, quanto ao papel dos Comitês de Bacia Hidrográfia. $\mathrm{Na}$ legislação estadual, previa-se a figura do Comitê de Bacia Hidrográfia com uma forma de organização dos usuários, a ser incentivada pelo Órgão Gestor (art. 6², inciso XVII), destinando-se a discutir e propor sugestões do interesse das respectivas bacias.

Bem mais amplos e abrangentes são, no particular, os COMITÊS DE BACIA HIDROGRÁFICA de que trata a Lei federal n 9.433/97, em seus arts. 37 a 39. Estes serão compostos de representantes da União, dos Estados e do Distrito Federal, dos usuários das águas em sua área de atuação, e das entidades civis de recursos hídricos com atuação comprovada na bacia hidrográfica respectiva. Vale salientar que, no caso de bacias hidrográficas com área de atuação restrita a rios sob domínio exclusivamente estadual, a participação da União terá uma disciplina especial, a ser estatuída através de seus respectivos regimentos (Art. $39, \S 4^{9}$ da Lei 9.433/97).

A Lei estadual $n^{2} 6.855 / 95$ estabeleceu, ainda, a divisão interna do território do Estado em dez Regiões Administrativas (RAA), com jurisdição sobre treze bacias hidrográficas estaduais.

11. Após o advento da Lei federal $\mathrm{n}^{0} 9.433 / 95$, o Decreto estadual $\mathrm{n}^{0} 6.295$, de 21 de março de 1997, veio a instituir o SISTEMA DE PLANEJAMENTO, COORDENAÇÃO E IMPLANTAÇÃO DO PROJETO DE GERENCIAMENTO DE RECURSOS HÍDRICOS DO ESTADO DA BAHIA (SISPLAC).

Referido Decreto procurou compatibilizar e harmonizar a legislação estadual com a federal que lhe sobreveio, dispondo a respeito da necessidade de cooperação e integração das atividades dos órgãos e entidades estaduais e destas com os organismos federais, nos termos da nova Lei federal citada.

Passam a compor o SISPLAC o CIRH - Conselho Interinstitucional do Projeto de Gerenciamento de Recursos Hídricos, e o COREH - Comitê Coordenador de Recursos Hídricos.

Ao CIRH cabe, entre outras atribuições, aprovar o Plano Estadual de Recursos Hidricos e encaminhá-lo ao Governador do Estado, bem como articular-se com outras Secretarias de Estado, em programas e projetos relacionados com recursos hídricos, meio ambiente, saúde, recreação, turismo e outros; e com a União, para ações conjuntas ou compatibilização do PGRH com programas federais de recursos hídricos e saneamento.

Quanto ao COREH, prevê o citado Decreto e sua articulação com entidades federais atuantes no setor de recursos hídricos, saneamento, irrigação e meio ambiente, para integração das suas ações, em especial a CODEVASF - Companhia de Desenvolvimento do Vale do São Francisco, o DNOCS - Departamento Nacional de Obras contra Secas, a SUDENE - Superintendência do Desenvolvimento do Nordeste, a ANEEL - Agência Nacional de Energia Elétrica e o INMET - Instituto Nacional de Meteorologia.

12. Completa-se a legislação estadual baiana específica de recursos hídricos com o Decreto $\mathrm{n}^{9}$ 6.296, de 21 de março de 1997, o qual, regulamentando os artigos 12,13,18 e 19. da Lei no 6.855 , de 12 de maio de 1995, veio a disciplinar a outorga 
do direito de uso de recursos hídricos e a aplicação de sanções pela infração às normas disciplinadoras do uso dos recursos hídricos do Estado.

Tal regulamentação incide sobre as águas do domínio do Estado relacionadas no art. $7^{\circ}$, inciso IV, da Constituição estadual (isto é, as mesmas águas de que trata o art. 26, icn. I, da Constituição Federal) e as águas do domínio federal situadas no território estadual, quando, conforme previsto no $\S 1^{0}$ do art. 12, da Lei federal 9.433/95, forem objeto de delegação pelo Governo Federal.

Estatui, o Decreto estadual $n^{9} 6.296 / 897$, sobre a proteção dos recursos hídricos contra degradação ou utilização predatória, e disciplina, com base na Lei 6.855/95, no Decreto $n^{2} 4.082$, de 27/03/95 e com observância das disposições pertinentes da Lei federal $n^{2}$ 9.433/97 e do Código de Águas, sobre a outorga do direito de uso das águas, através de concessão (até trinta anos) ou autorização (até quatro anos, renováveis por mais dois iguais períodos), a serem expedidas pela Secretaria de Recursos Hídricos. Saneamento e pela Superintendência de Recursos Hídricos, na forma do art. $9^{\circ}$ do Decreto n8 4.082, de 27/03/95. Para a devida orientação dos usuários sobre os procedimentos a serem formalizados, aliás, acaba de ser publicado, em obediência à determinação do art. 13, o Manual de Outorga de Direito de Uso da Água da Superintendência de Recursos Hídricos.

Em função das peculiaridades próprias do Estado da Bahia, tais como, por um lado, uma grande riqueza de recursos hídricos com potencial de aproveitamento energético, mas, de outro, a localização de grande parte de sua área no Polígono das Secas, o Dec. $n^{9}$ 6.296/97 teve extremas cautelas em delimitar:

a) a ordem das prioridades de uso das águas (art. 10, incisos I a VIII), entre as quais ocupam primeiro lugar o abastecimento humano e animal e a irrigação;

b) as providências para o racionamento do uso de recursos hídricos, em caso de escassez (art. 11);

c) os limites para o somatório das vazões a serem outorgadas (art. 14, incs. I a III, e seus $\S \S 1^{\varrho}$ a $3^{2}$; art. $15, \S \S 1^{\varrho} \mathrm{e} 2^{9}$ ), com previsão específica para a ocorrência de estiagens prolongadas.

A referida regulamentação reporta-se à legislação ambiental específica, quanto à outorga de lançamento de efluentes e resíduos líquidos (art. 15, § $3^{2}$ ).

Definem-se, ainda, nos arts. 18 a 29 , as penalidades a serem aplicadas pelas infrações leves, graves e gravíssimas, quais sejam a advertência (art. 19), as multas (arts. 20 a 24, e 32 a 36), os embargos administrativos, provisórios ou definitivos (arts. 25 a 28 ) e a revogação da outorga (arts. 29 a 31), prevendo, ainda, as normas de formalização do processo respectivo (arts. 35 a 39) e os recursos administrativos cabíveis (arts. 40 a 43), em obediência à garantia do art. $5^{\circ}$, inc. LV, da Constituição Federal.

Vale salientar que, consoante a própria Lei 6.855/95 dispõe, em seu artigo 22, serão estabelecidos mecanismos visando a articular os procedimentos e ações da SSRH com os do Centro de Recursos Ambientais da Bahia - CRA, em relação à proteção e ao combate à poluição de recursos hídricos no Estado.

13. Por usa vez, a matéria respeitante aos recursos hídricos do Estado se encontra estreitamente relacionada com as disposições da Lei estadual $\mathrm{n}^{2} 3.858$, de 3 de novembro de 1980 , a qual foi regulamentada pelo Decreto $\mathrm{n}^{-0} 28.687$, de 11 de 
fevereiro de 1982. Referida Lei já indicara, como objeto de proteção especial, os mananciais com influência na Região Metropolitana de Salvador (art. 21). Seu Regulamento dedica o Capítulo III às águas, classificando-as, para o efeito de proteção ambiental, definindo seus usos legítimos (art. 45), estabelecendo os critérios e padrões de qualidade das águas para tais usos legítimos (arts. 55 a 59), os critérios e padrões de qualidade para lançamento de efluentes (arts. 60 a 68), e também o sistema de licenciamento especial para atividades potencialmente causadoras de impacto ambiental, com suas normas próprias de fiscalização e sanções...

14. Agrupam-se, sob a jurisdição das dez RAA (Regiões Administrativas de Águas) criadas pela Lei estadual $n^{9} 6.855 / 95$, treze bacias hidrográficas bem delimitadas, com características próprias e acentuadas peculiaridades específicas.

De logo se evidencia, ao mais ligeiro exame, diversidade das problemáticas jurídicas configuradas por tais bacias hidrográficas. Temos bacias constituídas por cursos d'água comuns a outros Estados da Federação; bacias abrangidas pela Região Metropolitana da Grande Salvador; bacias cujos recursos hídricos constituem um grande potencial hidroenergético, como é o caso de algumas abrangidas por águas do rio São Francisco; aquelas vocacionadas para o transporte aquaviário; e, ainda, bacias hidrográficas que se incluem entre as zonas semi-áridas abrangidas pelo Polígono das Secas. E assim por diante.

A matéria relativa à gestão de recursos hídricos se apresenta, pois, no Estado da Bahia, particularmente complexa e inçada de dificuldades, em relação aos problemas de superposição de competências das ordens federadas, da compatibilização da política estadual de recursos hídricos com a legislação federal, da interferência com leis especiais, e quanto à competência própria dos municípios.

Cruzam-se as competências constitucionais da União, dos Estados Federados e dos Municípios, incidindo sobre os recursos hídricos. Pois, de um lado, legislar sobre águias em geral é da competência da União, que há de prevalecer sobre as demais ordens federadas. Mas a própria Constituição da República, como vimos, aponta, em vários de seus dispositivos, em mais de um aspecto peculiar em especial, por mais de uma maneira, para a necessidade da integração e articulação das competências dos demais entes da Federação, no que pertine à gestão dos recursos hídricos neles situados.

Não obstante caber à União, nos termos do inciso XIX do art. 21, a competência, aliás já devidamente exercitada através da recente Lei $\mathrm{n}^{0} 9.433 / 97$, para a instituição do Sistema nacional de Gerenciamento de Recursos Hídricos e para a definição dos critérios de outorga dos direitos de seu uso, verifica-se que esta mesma Lei não invalida, antes consagra, a realização dos planejamentos em nível regional e estadual, devendo a União articular-se com os Estados, com vistas ao gerenciamento dos recursos hídricos de interesse comum.

Mesmo assim, a tarefa torna-se delicada, na articulação do plano geral de recursos hídricos do Estado, para que não se efetuem invasões de competências.

O trabalho torna-se extremamente facilitado porquanto, no caso em questão, houve uma inversão do processo que comumente ocorre para a compatibilização de legislações federais e estaduais. A Lei 9.433/97 decorrera de uma longa discussão nacional entre os setores públicos interessados na solução do problema. Mas, como 
sofreu demasiado retardamento o advento da lei federal, muitas legislações estaduais se the anteciparam, naquilo em que poderiam constitucionalmente dispor, como foi o caso da própria legislação baiana.

Daí resultou vir a ser a lei $\mathrm{n}^{\mathrm{0}} 9.433 / 97$, afinal, basicamente inspirada nos mesmos princípios vetores que haviam inspirado os diplomas locais.

Isto, porém, não afasta, definitivamente, a necessidade das cautelas que deverão ser adotadas, para, ainda mesmo atendendo, como deve ser feito, as peculiaridades regionais e locais, respeitar-se a prevalência constitucionalmente consagrada, das diretrizes da legislação federal.

15. A mesma cautela que deverá nortear a elaboração do plano estadual de recursos hídricos, em relação ao respeito às diretrizes da legislação federal, também deverá presidir a sua compatibilização com as disposições da legislação municipal, notadamente as das leis orgânicas dos municípios. Constitucionalmente, a faixa de competência legiferante e de atividade administrativa dos municípios é pequenina, porém indevassável, quando se trate de atingir aos interesses que se revelem predominantemente locais das comunas. Para dispor sobre tais interesses, e somente para isso, os municípios podem exercer (e muitas Leis orgânicas assim já o fazem), a competência, também determinada pela Constituição, para suplementar a legislação federal e estadual, inclusive quanto aos próprios recursos hídricos.

Como já devidamente ressaltado, a extrema diversidade das condições peculiares das bacias hidrográficas do Estado torna particularmente complexa a elaboração do planejamento de recursos hídricos, no que diz respeito às interações e inteferências com aspectos que, por sua vez, se relacionam com outras legislações específicas, demandando sua compatibilização com a aplicação de regras especiais.

Alguns desses aspectos merecem mais detida atenção:

\section{I - Saneamento básico e abastecimento de água.}

São indissociáveis as problemáticas da gestão de recursos hídricos e do saneamento básico, abrangendo este o aspecto particular do abastecimento de água.

Como devidamente ressaltado, especificamente sobre tal matéria cede passo a competência legiferante da União, limitada apenas à expedição de diretrizes (art. 21, inc. $X X-C F)$, a serem complementadas pelos Estados, em prol da competência dos municípios, diretamente envolvidos na questão, por tratar-se de matéria de iniludível interesse local.

Têm alguns estudiosos fixado o entendimento segundo o qual a distribuição domiciliar da água e a retirada de esgotos é da exclusiva titularidade do Município, e que as disposições sobre competência comum, relativamente ao saneamento básico, que figuram no inciso IX do art. 23 da Constituição, apenas podem limitar-se à promoção da melhoria de condições no setor.

Mas a questão não é tão simples assim. Bem é de ver que o abastecimento d'água é estreitamente ligado à disponibilidade local de recursos hídricos. Se estes se localizam no próprio município, nenhum problema existe, em princípio. Mas, se o abastecimento d'água no município depender, por exemplo, de cursos d'água que 
provêm de outros municípios, será inevitável a interferência com a legislação própria de recursos hídricos em geral, ensejando a adoção de certas providências para sua adequada compatibilização legal e institucional.

É sempre lembrado, a propósito, o exemplo do Município de Salvador, cujo abastecimento de água potável depende do rio Joanes e do rio Paraguaçu, situados em outros municípios, em mais de uma bacia hidrográfica, e, parcialmente, no âmbito da Região Metropolitana da Grande Salvador, cuja competência, no caso, exsurge predominante.

De qualquer sorte, pois, o profundo inter-relacionamento entre os interesses públicos a serem envolvidos na questão enseja certa ordem de considerações, que tornam única, para cada caso concreto, a solução a ser adotada.

\section{Proteção ambiental}

Sendo a água recurso natural essencial à vida, porém o mais vulnerável deles, sua proteção constitui capítulo obrigatório da legislação sobre proteção ambiental, e todas as ações, no campo da gestão de recursos hídricos, passam obrigatoriamente pela observância de suas normas, como já devidamente observado.

Um aspecto essencial a ser considerado será a compatibilização das normas pertinentes ao mau uso das águas, bem como as sanções respectivas, com as disposições específicas e particularmente rigorosas da nova legislação ambiental, sobretudo a recente Lei federal $\mathrm{n}^{\circ} 9.605$, de 12 de fevereiro de 1998 , a qual dispõe sobre as sanções penais e administrativas derivadas de condutas e atividades lesivas ao meio ambiente.

Em muitos casos, coincidirão infrações e penalidades previstas, para os mesmos ilícitos, tanto, na legislação de recursos hídricos quanto na legislação ambiental, esta última, agora, com fortes repercussões na esfera penal.

\section{Aproveitamento energético de cursos d'água}

São consideráveis as interferências da legislação específica sobre o aproveitamento energético de cursos d'água sobre o planejamento da gestão de recursos hídricos, com a predominância incontestável da primeira, tendo em vista o caráter estratégico de que se reveste.

\section{Defesa contra calamidades públicas e recuperação de áreas áridas}

A colocação de boa parte do território do Estado da Bahia, bem como algumas de suas bacias hidrográficas, no Polígono das Secas, há de ser levada em conta, pela incidência, sobre a espécie, da legislação especial sobre o combate às secas, bem como da interferência das atividades de órgãos especificamente destinados às atividades pertinentes. 
Aliás, verifica-se. em relação à legislação estadual sobre o uso de águas, consubstanciada, particularmente, na Lei 6.855/95 e no Decreto $n^{0} 6.296$, de 21 de março de 1997, a preocupação com tais aspectos, em certos casos. Determina-se, até, a inversão das ordens de prioridade na determinação dos usos das águas, bem como o próprio afastamento de certas sanções.

\section{Turismo e lazer}

Toda a legislação sobre recursos hídricos, já devidamente analisada, não deixa de incluir o turismo e o lazer como parte do uso múltiplo das águas, com vistas ao próprio aproveitamento econômico de sua belezas naturais. Nesse particular, revela-se a existência de grande e apreciável potencial, ainda pouco explorado no Estado da Bahia, a demandar melhor interação entre a gestão dos recursos hídricos e a ação dos organismos estaduais inseridos na estrutura da Secretaria de Cultura e Turismo.

16. Anuncia-se, à base do que dispõe a Lei federal $n^{2} 9.433 / 97$ e a Lei estadual $\mathrm{n}^{2} 6.855 / 95$, bem como dos princípios estatuídos na Constituição Estadual, a elaboração de um Plano de Gestão de Recursos Hídricos, que irá compatibilizar as metas da Política Nacional de Recursos Hídricos com a as peculiaridades regionais, através do estudo pormenorizado das características e dos problemas de cada bacia hidrográfica. Visa-se, assim, à coordenação das ações da política de gestão dos recursos hídricos com a legislação específica em vigor, com vistas a uma perfeita articulação das ações federais, estaduais e municipais, bem como a integração, nas soluções a serem preconizadas, da legislação afim ou correlatada que também incide sobre certos aspectos relacionados com tais problemas.

Objetiva-se, assim, implementar, no Estado, um gerenciamento dos recursos hídricos que possua as seguintes características essenciais:

a) planejamento adequado, com a observância das peculiaridades locais e de ocupação do solo;

b) celebração de parceria entre municípios e estados no gerenciamento das águas, com a participação da comunidade;

c) fiscalização severa dos agentes poluidores, mesmo quando econômica e politicamente fortes.

d) promoção da educação ambiental, conscientizando-se a população para a necessidade de preservar-se esse recurso da natureza, tão precioso quanto particularmente escasso, em muitas regiões da Bahia,

Para tanto, não de ser adotadas algumas coordenadas mestras, a serem desenvolvidas em sua máxima potencialidade, quais sejam

1 - A consideração de que a água, bem de domínio público, de uso comum de todos, é um recurso natural essencial, porém finito e limitado, dotado de apreciável valor econômico, destinado ao uso múltiplo, que há de ser objeto de uma gestão descentralizada, com a participação conjunta do poder público, dos usuários e das comunidades organizadas.

2 - A utilização racional e integrada dos recursos hídricos deverá ter em vista o princípio do desenvolvimento sustentável, para que seja assegurada sua plena disponibilidade para a geração atual e as futuras. 
3 - A gestão sistemática dos recursos hídricos deverá ser adequada às diversidades físicas, bióticas, demográficas, econômicas, sociais e culturais das diversas regiões, em integração, sempre, com a necessidade de preservação do meio ambiente, em todos os seus aspectos essenciais.

4. A extrema importância da disponibilidade plena de recursos hídricos para as necessidades atuais e futuras da coletividade transcende as diversidades políticas regionais e locais, merecendo a articulação conjunta dos poderes públicos, dos usuários e da comunidade, todos convergentes para uma única finalidade, que é a otimização do uso das águas, priorizada apenas em função da ordem de suas necessidades.

5. A adequada utilização dos recursos hídricos, através de um conjunto de ações de planejamento, gestão e preservação, poderá ser um poderoso instrumento para o desenvolvimento econômico, o bem-estar e o progresso do Estado.

6. A cobrança pela utilização das águas, à semelhança do que se faz, com êxito, em outros países, especialmente Alemanha e França, como forma de conscientizar os usuários da sua importância, e de que se trata de produtos renovável, porém finito; para diminuir o seu consumo e evitarem-se desperdícios; para incentivar a sua utilização racional, possibilitando uma distribuição mais eqüitativa; adaptação das normas de sua cobrança às realidades sócio-econômicas efetivamente existentes, sabretudo em regiōes semiáridas.

17. Já dispomos, no Estado da Bahia, conforme a detida análise efetuada, de um adequado potencial de instrumento jurídicos, os quais, devidamente utilizados, podem conduzir à obtenção de soluções adequadas para os diversos e complexos problemas a serem enfrentados.

Mas ainda necessitam de complementação, a ser obtida através de um conjunto de medidas legislativas paralelas, em âmbito estadual, visto que ainda permanece uma certa defasagem cronológica, entre a legislação estadual e a recente legislação federal que the sobreveio, não obstante seja facilmente contornável.

No decorrer da estruturação do anunciado Plano de Gestão de Recursos Hídricos do Estado, será necessária a edição de leis e regulamentos que, por exemplo, compatibilizem devidamente as ações e competências dos Comitês de Bacia Hidrográfica federais e de suas Agências de Águas, ainda não suficientemente reguladas, com as regras de implantação e coordenação das Regiões Administrativas de Águas estaduais.

Por outro lado, com a nova redação do art. 241, da Constituição, pela Emenda $\mathrm{n}^{2} 19$, recomenda-se a paralela adoção, nos programas de gestão de recursos hídricos de certas bacias hidrográficas, de soluções incentivadoras da formação de consórcios públicos que assegurem a cooperação associativa de municípios, e até de estados vizinhos, se for o caso, em torno de problemas e peculiaridades comuns, com vistas ao interesse maior de assegurar a adequada utilização do bem essencial da vida, que é a água. 


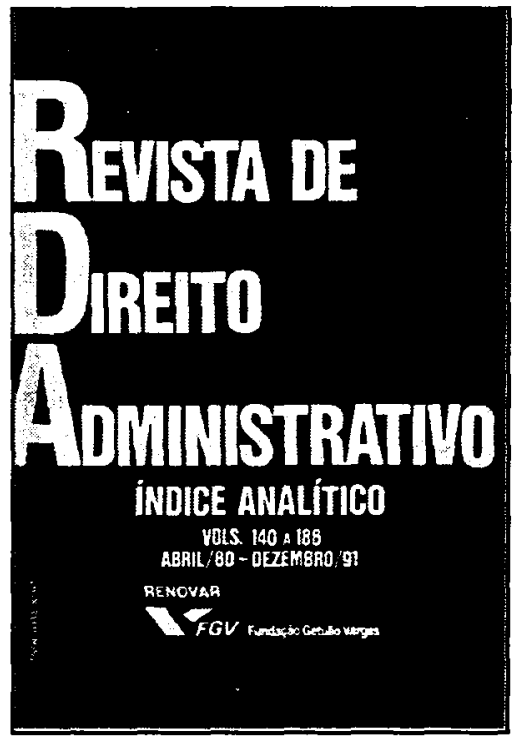

Ref. 0055

Ref. 0089

Cartonado

Form. 16x23

1991-1995

\section{ÍNDICE ANALÍTICO \\ DA REVISTA \\ DE DIREITO \\ ADMINISTRATIVO - RDA}

Vols. 140 a 186

Vols. 187 a 198

Indispensável como fonte de consulta para facilitar a localização, sem perda de tempo, dos respectivos assuntos apresentados na Revista de Direito Administrativo 